\title{
PATHWAYS OF CARBOHYDRATE FORMATION IN MAN. II. THE EFFECT OF DIABETES AND GLUCOCORTICOID ADMINIS- TRATION ON ISOTOPE DISTRIBUTION IN GLUCOSE FROM SUBJECTS GIVEN 1-C 14-ACETATE ${ }^{1,2}$
}

\author{
By WALTON W. SHREEVE AND ALLEN R. HENNES 3
}

(From the Medical Department, Brookhaven National Laboratory, Upton, N. Y.)

(Submitted for publication January 28, 1958; accepted March 20, 1958)

The pattern of glucose labeling after administration of $1-C^{14}$-acetate in nondiabetic human subjects has been established $(1,2)$ and found to be essentially the same as observed with animals using various odd-carbon-labeled fatty acids as precursors $(3,4)$. Such isotopic studies have supported the concept of transfer of fatty acid carbon to glucose by way of the tricarboxylic acid cycle and the glycolytic reactions, i.e., the classical route of glucose synthesis from various noncarbohydrate precursors. Whether these same reactions are solely utilized in those diabetic states in which overproduction of glucose is a possible contributing factor remains a question conceivably answerable by similar study with position-labeled compounds. Paramount to the question is the possible utilization of a pathway which, unlike the classical route of glucose synthesis, would afford a net gain in carbohydrate from fat. Major changes in the kind or quantity of available substrates, available coupling reactions, and so forth, might conceivably alter existing pathways or set in operation others which would eventuate in gluconeogenesis from fat in significant amounts.

The present study of isotope distribution in glucose after administration of trace amounts of 1-C $\mathrm{C}^{14}$-acetate has been conducted with various types of diabetic patients, including some with fully developed ketosis and acidosis and others in whom has been tested the effect of administration of an adrenal glucocorticoid. In confirmation of another such study in the diabetic dog (5), the findings in brief have not disclosed the abnormal utilization of pathways other than those previously

\footnotetext{
1 This research was supported by the Atomic Energy Commission.

2 The findings were presented in part at the Annual Meeting of the Federated Societies for Experimental Biology, 1956 (1).

${ }^{3}$ Present address: Veterans Administration Hospital, Oklahoma City, Okla.
}

assumed to account for glucose formation in the diabetic as well as the normal state. The total amount of $\mathrm{C}^{14}$ converted to glucose, however, has again suggested overproduction of glucose, particularly in acute ketotic diabetes.

\section{EXPERIMENTAL SUBJECTS}

Subject $V . P$. This patient was an 11 year old white female; weight, $37 \mathrm{Kg}$; height, $139 \mathrm{~cm}$. Her diabetic condition had been known to be present since the age of six. Severe acidosis was present at the time of discovery of diabetes, and insulin shock occurred in the course of initial regulation. The patient had required at various times since onset from 4 units to 50 or 60 units insulin per day. During the present hospital admission it was difficult to control glycosuria, hyperglycemia and occasional acetonuria without development of mild signs and symptoms of hypoglycemia. Four days prior to the isotopic study, the daily insulin course was changed from 30 units regular insulin plus 35 units protamine zinc insulin to regular insulin four times daily (25-8-8-8 units). On the day prior to study the usual 1,800 calorie diet (149 Gm. carbohydrate, $93 \mathrm{Gm}$. protein, $92 \mathrm{Gm}$. fat) was substituted by one containing $100 \mathrm{Gm}$. fat and $100 \mathrm{Gm}$. protein (hamburger and butter pats) evenly divided among three meals. No food was given after 6 p.m. On this day the patient received 20 units regular insulin at 8 a.m. and 5 units at 12 a.m. and no further insulin prior to study. At 5 p.m. the blood sugar was $192 \mathrm{mg}$. per cent, plasma $\mathrm{CO}_{2}$ was $24.4 \mathrm{mEq}$. per $\mathrm{L}$., and the urine strongly positive for acetone. At the time of injection of isotope the next day the patient was clinically acidotic, the blood sugar was $362 \mathrm{mg}$. per cent, and the plasma $\mathrm{CO}_{2}$ was $6.7 \mathrm{mEq}$. per L. (Figure 1).

Subject $H . R$. This patient was a 38 year old white female; weight, $57 \mathrm{Kg}$.; height, $160 \mathrm{~cm}$., with an onset of diabetes 11 years before. Regulation of diabetes by diet and insulin ( 30 to 50 units daily) was relatively easy until the advent two years before the present study of a pregnancy, during and after which bouts of acidosis and insulin shock were characteristic. For 10 days prior to study the patient received no long-acting insulin, but regular insulin four times daily (approximately 12-1212-4 units). On the day before the planned study, the patient's customary 2,100 calorie diet $(217 \mathrm{Gm}$. carbohydrate, $95 \mathrm{Gm}$. protein, $92 \mathrm{Gm}$. fat) was changed to 


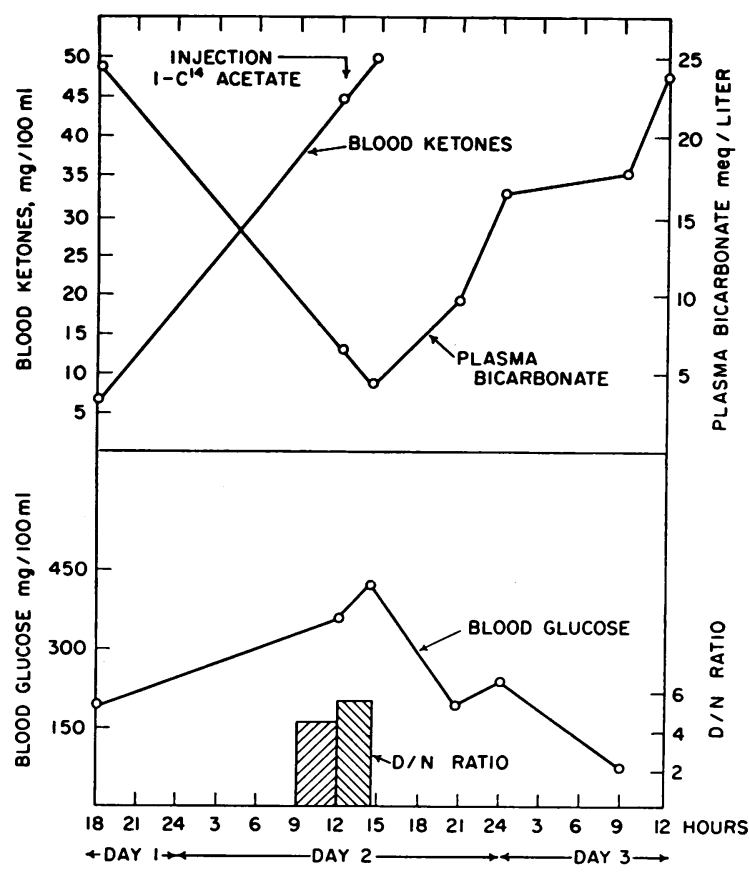

Fig. 1. Lab Data for Period of $C^{14}$ Study with Labile Diabetic Subject V. P., Female, Aged 11

$100 \mathrm{Gm}$. fat and $100 \mathrm{Gm}$. protein as with Subject V. P. No insulin was given after the eight a.m. dose of 12 units. The urine was 4 plus positive for sugar and acetone during the day and the patient became clinically acidotic late in the day. Due to the clinical state and blood chemistry (blood sugar equaled $664 \mathrm{mg}$. per cent, plasma $\mathrm{CO}_{2}$ equaled $13.6 \mathrm{mEq}$. per L., Figure 2) it was considered advisable to proceed with injection of the isotopic compound at one a.m.

Subject $M . M$. This patient was a 34 year old white female; weight, $71 \mathrm{Kg}$; height, ca. $160 \mathrm{~cm}$. Detection of diabetes three and one-half years prior to study was accompanied by findings of obesity ("buffalo type"), hirsutism, sparse scalp hair, and hypertension (230/160). Diabetes was established by the glucose tolerance test. An insulin tolerance test indicated moderate insulin resistance. Diabetes was readily controlled by diet alone and occasionally in conjunction with insulin. The blood hemoglobin was $15.5 \mathrm{Gm}$. per cent. There were no eosinophils found either on differential or quantitative eosinophil count. The 17-ketosteroids in a 24 hour urine sample were $3.06 \mathrm{mg}$. per cent and the plasma $17-\mathrm{OH}$ steroids were $25 \mu \mathrm{g}$. per cent basal going to $87 \mu \mathrm{g}$. per cent upon stimulation with adrenocorticotrophic hormone (25 units intravenously in six hours). Cardiac decompensation and hepatomegaly characterized the later course of this patient, as did some renal impairment (4 plus albuminuria, blood urea nitrogen of $38 \mathrm{mg}$. per cent). Prior to isotopic study the patient was receiving a balanced 1,000 calorie diet and no insulin. At the time of $\mathrm{C}^{14}$ injection the patient had been fasting approximately 18 hours since the previous evening. Blood sugar at the time of injection was $218 \mathrm{mg}$. per cent.

Subject $D$. $M$. This patient was a 59 year old white male; weight, $64 \mathrm{Kg}$. ; height, $168 \mathrm{~cm}$., whose diabetes was detected 12 years before. The disease was controlled by a 30 pound weight reduction, and no insulin was required until five months previous to admission, when intermittent glycosuria forced the use of 25 to 40 units $\mathrm{NPH}$ insulin daily. In the hospital, glycosuria and hyperglycemia were quite readily controlled with a 2,000 calorie diet $(240 \mathrm{Gm}$. carbohydrate, $80 \mathrm{Gm}$. protein, 80 $\mathrm{Gm}$. fat) and 25 to 40 units insulin. Arteriosclerosis and neuropathy moderately affected the lower extremities; there was 1 plus albuminuria and punctate retinal aneurysms were present. The patient received no insulin after the usual dose of $\mathrm{NPH}$ on the morning 72 hours prior to isotopic study. After the evening meal 40 hours prior to study food was withheld. Four plus acetonuria appeared at nine p.m. of the day before study and remained continuously until after the experimental period. Ketonuria cleared after feeding was resumed and before insulin was given. There was no glycosuria before or during the isotope experiment. The blood sugar was 181 mg. per cent at time of study and the plasma $\mathrm{CO}_{2}$ was $23 \mathrm{mEq}$. per L. (Figure 3). Nine hours and again at three hours prior to study the patient received $30 \mathrm{mg}$. prednisone (delta-1-cortisone) orally. On another occasion this dose of steroid produced in D. M. a drop of plasma eosinophils from 112 to 1.5 per cu. $\mathrm{mm}$.

Subject $P$. R. This patient was a 55 year old white male; weight, $82 \mathrm{Kg}$; height, $169 \mathrm{~cm}$. Diabetes was

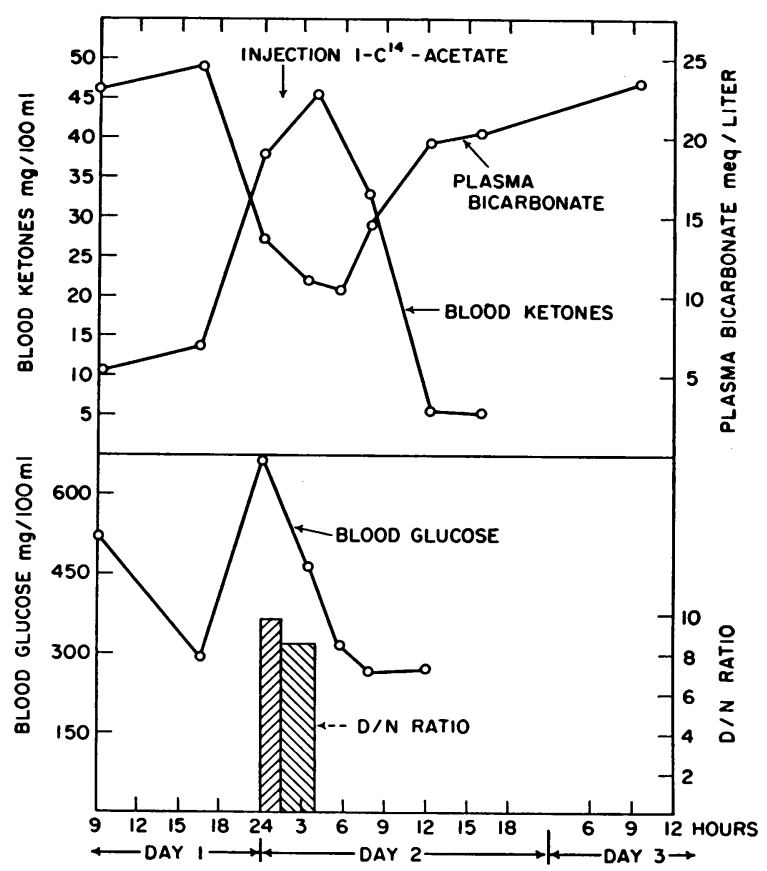

Fig. 2. Lab Data for Period of $C^{14}$ Study with Labile Diabetic Subject H. R., Female, Aged 38 


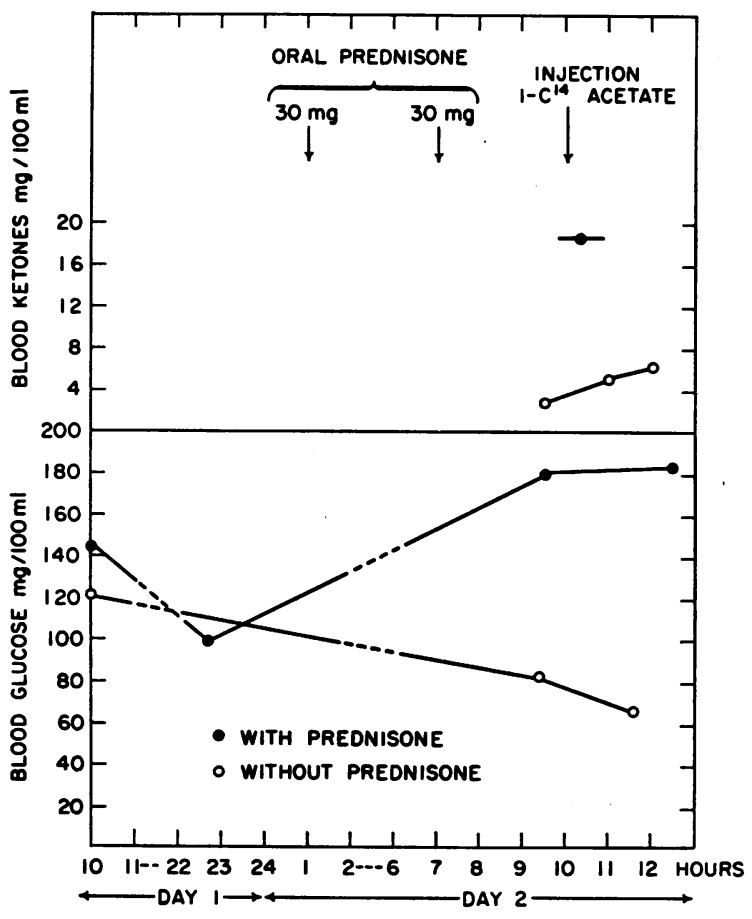

Fig. 3. Lab Data for Period of C $C^{14}$ Study with Stabile Diabetic Subject D. M., Male, Aged 59

discovered five years previously during the course of work-up for hypertension. He had no symptoms of diabetes at that time and was treated with diet alone. His fasting blood sugar gradually rose to about $250 \mathrm{mg}$. per cent, and one month prior to isotopic study he was started on 20 units Lente insulin. During two weeks of hospital admission prior to study, his diabetes was readily controlled with a daily dose of 35 units Lente insulin, while the patient was on a diet of 2,200 calories $(226 \mathrm{Gm}$. carbohydrate, $100 \mathrm{Gm}$. protein, $101 \mathrm{Gm}$. fat) with lowsodium content. During this time his weight decreased by approximately $4 \mathrm{Kg}$. The patient had no signs or symptoms of degenerative changes accompanying diabetes. The blood pressure was $218 / 126$, and the liver was palpable one fingerbreadth below the costal margin. Seventy-two hours before study the patient received the last dose of Lente insulin and 48 hours before study, a final dose of regular insulin. Food was withheld for 40 hours prior to isotope injection. At nine and at three hours prior to study he received $30 \mathrm{mg}$. prednisone by mouth. There was no glycosuria before or during the study, but the urine became strongly positive for acetone at four p.m. of the day preceding study and remained so until the latter part of the next day after restoration of food and insulin. At the time of isotope injection the blood sugar was $172 \mathrm{mg}$. per cent and the $\mathrm{CO}_{2}$ was 26 mEq. per L. (Figure 4).

\section{METHODS}

In each case 80 to 100 microcuries of $1-C^{14}$-sodium acetate (with $1.0 \mathrm{mM}$ reagent sodium acetate for carrier in
15 to $25 \mathrm{ml}$. of 0.9 per cent $\mathrm{NaCl}$ ) was given by rapid antecubital intravenous injection. Blood samples were taken at intervals for analysis of glucose by the methods of Miller and Van Slyke (6) or Mendel, Kemp, and Myers (7), analysis of ketone bodies by the method of Michaels, Margen, Liebert, and Kinsell (8), and $\mathrm{CO}_{2}$ of plasma by the method of Peters and Van Slyke (9). Nonprotein nitrogen in the urine was measured according to a slight modification of Peters and Van Slyke (10) and Kingsley (11). Approximately two hours after injection of the labeled acetate a blood sample of about $100 \mathrm{ml}$. was withdrawn from the opposite arm. From this sample glucose was isolated as previously described (2), except that for two subjects (P. R. and D. M.) the glucose was additionally purified by chromatography with acetone-water on cellulose columns (12) following elution from ion exchange columns. The glucose was degraded by fermentation with Leuconostoc mesenteroides and subsequent chemical steps followed by analysis of $\mathrm{C}^{14}$ in gaseous carbon dioxide as elsewhere described (2). Phenylglucosazones were prepared and analyzed as before (2).

\section{RESULTS}

The blood levels of ketone bodies and plasma $\mathrm{CO}_{2}$ in Subjects V. P. (Figure 1) and H. R. (Figure 2) leave no doubt that in these subjects the iso-

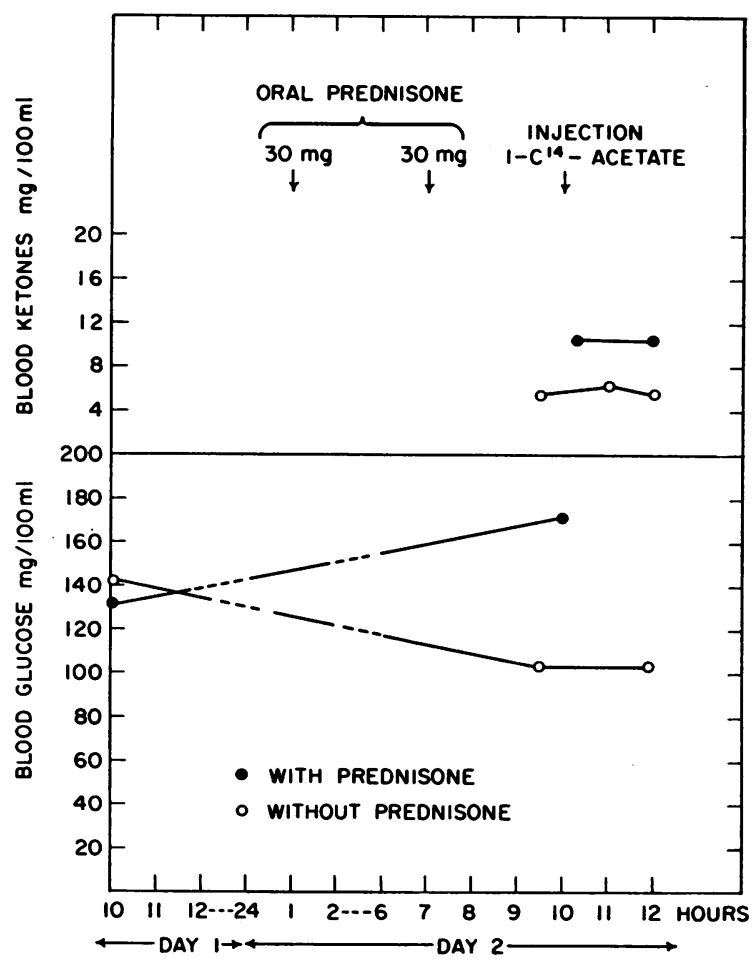

Fig. 4. Lab Data for Period of $C^{14}$ Study with Stable Diabetic Subject P. R., Male, Aged 55 
topic acetate was being metabolized at a time of acute ketotic diabetes. It was considered necessary to produce this condition since certain hypotheses of abnormal routes of formation of glucose involve acetoacetic acid as an intermediate compound (vide infra), and since a similar ketosis was present in another human study which claimed to demonstrate gluconeogenesis from fat on the basis of high urinary $\mathrm{D} / \mathrm{N}$ ratios (13). The purpose of modifying the diet in these two patients to one of fat and protein on the day before study was to eliminate dietary carbohydrate as a source of urinary glucose and thus make possible the interpretation of a high urinary $\mathrm{D} / \mathrm{N}$ ratio. If there were no source of circulating carbohydrate other than protein and fat, then gluconeogenesis from fat would be suggested by a urinary $D / N$ ratio above a certain value, theoretically as high as about 6 (13-15), but actually perhaps no more than 3 or 4 (16), assuming the utilization of some glucose by the tissues $(15,17)$. Both Subjects V. P. (Figure 1) and H. R. (Figure 2) exceeded the lower range, but only $H$. $R$. exceeded the higher estimate. It is doubtful, however, if the period of adjustment to a change in diet was sufficiently long to deplete liver glycogen, particularly in the case of H. R., to allow for any valid interpretation in regard to gluconeogenesis from fat.

It was considered that the other three diabetic patients, M. M., D. M., and P. R., might serve to test the condition of abnormal gluconeogenesis as related to glucocorticoid action. The diabetes of M. M. was associated according to clinical signs with adrenal corticoid hyperactivity, though laboratory findings did not definitely confirm (or deny) this. With Subjects D. M. and P. R., who were typically stable, obese diabetics, an elevation of blood sugar occurred following the administration of the synthetic glucocorticoid, delta-1-cortisone. Under the same conditions without glucocorticoid administration the blood glucose levels did not rise (Figures 3 and 4). In both instances, i.e., with and without delta-1-cortisone, both patients displayed a similar degree and time of onset of ketonuria (cf. Experimental Subjects) and mild ketonemia (Figures 3 and 4). The subjection of $\mathrm{Pa}$ tients D. M. and P. R. to a 40 hour fast prior to study was again for the purpose of interpreting a $\mathrm{D} / \mathrm{N}$ ratio unaffected if possible by consumed or stored carbohydrate, but the moderate degree of hyperglycemia was not accompanied by any urinary output of glucose.

In Table $I$ are given the results of degradation of glucose and isotopic analysis of each carbon fraction for all of the diabetic subjects. Just as was found with nondiabetic human subjects $(1,2)$, virtually all (96 to 98 per cent) of the glucose $C^{14}$ was located in the carbon 3 and carbon 4 positions. Activity in carbon 4 was in each case higher than that in carbon 3 but to a variable extent (10 to 50 per cent). Specific activities of carbons $1,2,5$, and 6 varied from 0.2 to 1.6 per cent of the total glucose $\mathrm{C}^{14}$. The validity of these low percentage activities has been previously ascertained $(2,18)$. The low absolute levels of radioactivity of these carbon fractions and resultant high counting errors (Table I) would yet seem to permit the conclusions that activities of carbons $1,2,5$, and 6 relative to carbons 3 and 4 are approximately the same as in nondiabetic subjects and that, as in the latter case (2), carbons 1 and 2 have activities quite similar to each other and generally higher than the activities of carbons 5 and 6 . Blood glucose, collected from Subjects V. P. and H. R. two hours after $\mathrm{C}^{14}$ administration, was also degraded with less complete results, but showed essentially the same distribution of $\mathrm{C}^{14}$ as was found with urinary glucose.

From the $\mathrm{C}^{14}$ activities of phenylglucosazones of blood glucose and the blood glucose level at two hours after isotope injection, the total amount of $\mathrm{C}^{14}$ in free body glucose [presumed to be equally distributed in a hypothetical "space" equal to 20 per cent of total body weight (2)] was calculated. From these values it was estimated that the fraction of injected $\mathrm{C}^{14}$ present in total free body glucose at two hours after administration of 1-C 14acetate was as follows: V. P. equals 4.2 per cent," H. R. equals 3.6 per cent, ${ }^{4}$ M. M. equals 1.7 per cent, D. M. equals 1.8 per cent, and P. R. equals 2.4 per cent. Values for V. P. and H. R. (the two unstable and strongly ketotic diabetics) are considerably higher than those found in four nondiabetic subjects (average of 1.5 per cent, range of 1.2 to 1.8 per cent) (2). Values for the other three (stable) diabetic subjects are not signifi-

\footnotetext{
4 For V. P. an additional 0.7 per cent of the injected $\mathrm{C}^{14}$ was present in urinary glucose excreted during the first two hours after administration, and for $H$. R., an additional 0.2 per cent.
} 
Table I

Distribution of $\mathrm{C}^{14}$ in glucose* following I.V. administration of $1-\mathrm{C}^{14}$ sodium acetate ( 50 to 100 microcuries in $1.0 \mathrm{mM}$ ) to diabetic human subjects

\begin{tabular}{|c|c|c|c|c|c|c|c|c|c|c|}
\hline \multirow{2}{*}{$\begin{array}{l}\text { Glucose } \\
\text { carbon } \\
\text { fraction }\end{array}$} & \multicolumn{2}{|c|}{ Subject V.P.** } & \multicolumn{2}{|c|}{ Subject H.R.** } & \multicolumn{2}{|c|}{ Subject $M_{.} M_{i} \dagger$} & \multicolumn{2}{|c|}{ Subject D.M. ${ }^{\prime}$} & \multicolumn{2}{|c|}{ Subject P.R.t } \\
\hline & s.a.tt & $\% t+t$ & s.a. & $\%$ & s.a. & $\%$ & s.a. & $\%$ & s.a. & $\%$ \\
\hline C-1 & 10 & .6 & 5 & .4 & 4 & .8 & 9 & .8 & 10 & 1.4 \\
\hline C-2 & 12 & .7 & 8 & .7 & 9 & 1.6 & 7 & .6 & 10 & 1.4 \\
\hline C-3 & 841 & 47. & 496 & 43. & 258 & 47. & 491 & 42. & 272 & 39. \\
\hline C-4 & 917 & 51. & 626 & 55. & 273 & 50. & 648 & 56. & 410 & 58. \\
\hline C-5 & 5 & .3 & 5 & .4 & 5 & .9 & 4 & $.4^{\circ}$ & 3 & .4 \\
\hline C-6 & 5 & .3 & 3 & .3 & 1 & .2 & 2 & .2 & 2 & .2 \\
\hline
\end{tabular}

*For V.P., urinary glucose excreted 2.5 to 7 hours, and for H.R., urinary glucose excreted 3 to 4 hours after $C^{14}$ administration; for M.M., D.M., and P.R. blood glucose collected 2 hours after administration (variably diluted with carrier glucose prior to is otopic analysis).

**Unstable diabetics in ketoacidosis.

tStable diabetics.

††Specific activity = disintegrations/minute/milligram carbon; standard deviation of sampling and counting, where S.D. $=\sqrt{\sqrt{n(n-1)}}$, was 5 percent or less for $C-3$ and $C-4$,

5 to 25 percent for $C-1$ and $C-2$, and 15 to 100 percent for $C-5$ and $C-6$. tftPer cent of total glucose $C^{14}$ contained in each carbon fraction.

cantly higher on the average than for nondiabetic subjects. Furthermore, in the "control" studies of D. M. and P. R. without steroid administration, the amounts of $\mathrm{C}^{14}$ found in blood glucose two hours after $\mathrm{C}^{14}$-acetate administration were essentially the same as with steroid administration, i.e., 1.9 per cent and 2.4 per cent for D. M. and $P$. R., respectively. Thus, in spite of the apparent hyperglycemic effect of the synthetic glucocorticoid no more acetate radiocarbon was converted to glucose. A factor of uncertainty in the calculation is a question as to whether the ketotic, acidotic diabetics (V. P. and H. R.) could be considered to have a contracted extracellular fluid space (and therefore contracted volume of distribution of glucose) as a result of partial dehydration. Such an effect would render the estimation of amount of $\mathrm{C}^{14}$ in glucose unduly high.

\section{DISCUSSION}

The controversial evidence on gluconeogenesis from fat in mammalian species has been repeatedly reviewed and discussed $(4,14,19-22)$. To summarize in brief, while classical balance studies have generally failed to demonstrate extra formation of carbohydrate from fat fed to experimentally diabetic animals $(19,21)$, other quantitative studies with perfused organs and tissue slices $(14,23-25)$ as well as intact animals $(14,26,27)$ and humans (13) have indicated from consideration of respiratory quotients, dextrose/nitrogen ratios, and various other data on carbon balance, that under certain experimental conditions some fatty acid as well as protein (amino acids), glycerol, or lactic acid may contribute to an increase in amount of carbohydrate.

Isotopic findings, such as the formation of primarily 3, 4-labeled glucose from carboxyl-labeled fatty acids $(2-4)$, have generally supported the original concept that the main intermediary metabolic pathways permit the conversion of fatty acid carbon to glucose but without net gain in amount of carbohydrate. Nevertheless, there have been reasons for postulating that under some special and abnormal conditions a different pattern of labeling in glucose might be produced which would disclose a pathway for gluconeogenesis from fatty acids. For instance, 2-C ${ }^{14}$-labeled acetone was 
found to label the $1,2,5$, and 6 carbons of glucose (28) and the 2 carbon of alanine (29) to such an extent as to suggest a major disposal of acetone by conversion possibly through propanediol (30) to a 3 carbon compound such as pyruvate. Since acetoacetic acid may be actively decarboxylated to acetone (31), a series of reactions, such as in Figure 5, could be conceived for net formation of glucose accompanied by an abnormal pattern of $\mathrm{C}^{14}$ distribution in the glucose derived from a carboxyl-labeled fatty acid. It seemed worthwhile to put this hypothesis (and others mentioned below) to a clinical test with diabetic patients in a state of advanced ketosis, in which high tissue concentrations of ketone bodies in the liver (and perhaps kidney) might result in marked acceleration of a pathway like that shown in Figure 5.

Alpha oxidation of beta-hydroxybutyric acid was suggested twenty years ago (23) in order to explain increase in amount of carbohydrate and lactic acid after presentation of butyric acid, betahydroxybutyric acid, and alpha, beta-dihydroxybutyric acid to surviving tissues (muscle, kidney, spleen, brain, and liver) of cats and dogs. Such a pathway would presumably label the outer carbons of glucose after administration of a carboxyllabeled fatty acid. Omega (terminal methyl carbon) oxidation of butyric acid to succinic acid was early suggested (24) to be responsible for an observed net formation of carbohydrate and would also form 1, 2, 5, and 6-carbon-labeled glucose, from $1-C^{14}$-acetate, as would a similar conversion of acetoacetic or beta-hydroxybutyric acids. In ketosis one would expect the latter to be more likely than the former according to current concepts of a block in diabetes between "ketone bod- ies" and butyrate (32). Another reaction which might eventually form in net quantity $1,2,5$, and 6-labeled glucose from $1-\mathrm{C}^{14}$-acetate is the reversal of the oxidative decarboxylation of pyruvate. Though this occurrence is most unlikely from thermodynamic considerations, some evidence was obtained for potential reversibility of the immediate reaction of decarboxylation in a pig heart muscle system (22).

The finding of the normal labeling pattern in glucose from blood and urine of diabetic patients given $1-\mathrm{C}^{14}$-acetate indicates that none of the above postulated pathways was responsible for glucose formation in significant amount in the liver. The suggested pathways involving "ketone bodies" were not undetected because of failure of transfer of $\mathrm{C}^{14}$ to acetoacetate and beta-hydroxybutyrate, since the labeled ( 1 and presumably 3 ) carbons of the latter in the urine were found to have $\mathrm{C}^{\mathbf{1 4}}$ activities of the same order as the 3 and 4 carbons of glucose from the same patients (unpublished observations). The results therefore coincide with similar findings from the use of 3-labeled butyrate in normal rat liver (3) and cat heart muscle (33), 1,3-labeled acetoacetate in normal rat liver (28) and 3-labeled acetoacetate in dog heart muscle (34). Moreover, the results are parallel to those obtained in the only other similar study in a diabetic organism, i.e., the totally pancreatectomized dog (5), in which tracer was detected only in the 3 and 4 carbons of glucose after administration of 1-C14-tripalmitin. In the latter instance, the animals were heavily glycosuric, but the state of ketosis was not defined as in the present investigation with diabetic patients.

It should be recognized that the conventional

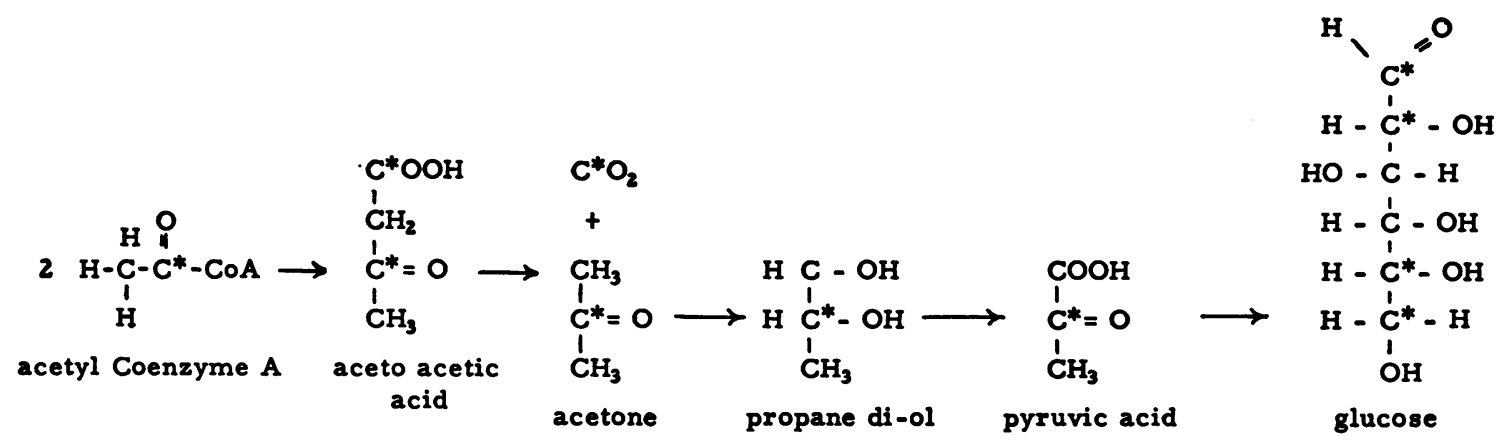

Fig. 5. Reactions Forming Glucose from Acetate Via Acetoncetate and Acetone Asterisks indicate location of $\mathrm{C}^{\mathrm{M4}}$. 


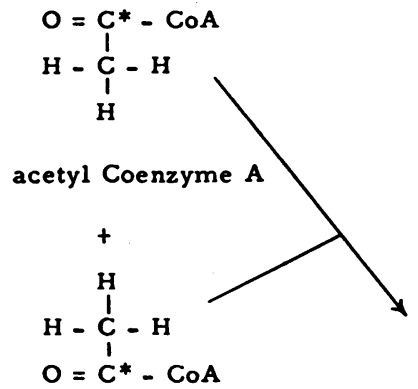

acetyl Coenzyme $A$

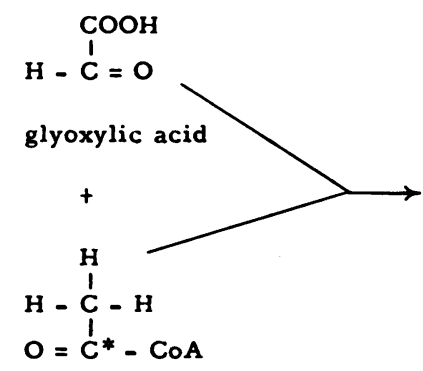

acetyl Coenzyme $A$<smiles></smiles>

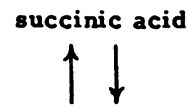<smiles>O=C(O)C(O)[C@H](CO)C(=O)O</smiles>

malic acid

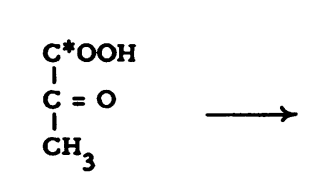

pyruvic acid

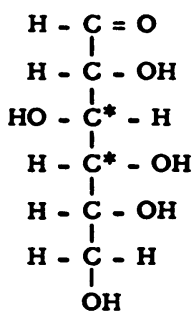

glucose

Fig. 6. Reactions Forming Glucose from Acetate Via "Tall-to-Tail" Condensation to Succinate and Condensation with Glyoxalate to Malate

Asterisks indicate location of $\mathrm{C}^{\mathbf{1 4}}$.

labeling pattern found with odd-carbon-labeled fatty acid does not exclude all possible means of net formation of glucose. The early suggestion (35) of a "tail-to-tail" condensation of two molecules of acetate to form succinate (upper section of Figure 6) and then obviously net carbohydrate is a reaction consonant with present isotopic data. Evidence has been produced for an enzyme from rat (36) and rabbit (37) tissues which cleaves succinate in this manner, but reversibility in mammalian species, if it occurs, is apparently slow and inconsistent $(36,38,39)$. A reaction postulated quite recently from evidence in microorganisms $(40,41)$ and plants $(41)$ is a condensation of acetic acid $^{5}$ with glyoxylic acid to form malic acid, as in the lower section of Figure 6 . This reaction, whether or not involved in a "glyoxylic acid cycle" (41), would form net quantities of carbohydrate from 2 carbon fragments of fat

\footnotetext{
5 Active derivative (with CoA) would be more precise, as for many intermediates mentioned in this discussion, but such have been omitted for purposes of brevity and clarity.
}

metabolism and is consistent with, though not specifically indicated by, present data on glucose labeling. A recent attempt to demonstrate the requisite enzymatic reactions in animal tissues was unavailing, however, even under the condition of excessive fat feeding (42).

The trace amounts of $\mathrm{C}^{14}$ found in the $1,2,5$, and 6 carbons of glucose from patients in this study are not considered to have been derived by any of the mechanisms suggested above, because if so by initial formation of 2,3-labeled pyruvate carbons 5 and 6 of glucose would have had equal or higher activities than carbons 1 and 2, [(2) and vide infra], unless glycerol or dihydroxyacetone is a product of acetone oxidation rather than pyruvate. The similarity in amount and distribution of $\mathrm{C}^{14}$ in these carbons to that found with nondiabetic patients would suggest the operation, as previously mentioned (2); of the oxidative and nonoxidative reactions of the pentose phosphate cycle. If any difference from findings in control subjects exists at all, it is in the direction of generally lower activities relative to carbons 3 
and 4 , which could be merely a reflection of increased glucose synthesis relative to an unchanged rate of reactions responsible for $\mathrm{C}^{\mathbf{1 4}}$ in the $1,2,5$, and 6 carbons. In view of various observations of the effect of diabetes $(43,44)$, cortisone $(44)$, and starvation $(43-45)$ on activity of the pentose phosphate cycle, it is perhaps noteworthy that no major differences in the amount and pattern of $1,2,5$, and 6-glucose carbon labeling were detected as a result of nutritional and hormonal changes in the present study.

Reasons for difference in $\mathrm{C}^{14}$ content of carbons 3 and 4 with regard to mechanisms of glucose formation have been discussed in a preceding publication (2). Current theory, on the basis of nonequilibration of triose units, would predict disparity of carbons 3 and 4 in proportion to the amount of substrate available for glycolytic intermediates. It is not seemingly possible to interpret the variable differences of carbon 3 and carbon 4 activity found in the diabetic or nondiabetic patients on any nutritional or hormonal basis. The larger differences between carbons 3 and 4 in the 40 hour fasted subjects than in those fasted for considerably shorter periods does not coincide with the current theory on the basis of fasting per se, since the fasting state would presumably tend to equilibration of dihydroxyacetone phosphate and phosphoglyceraldehyde.

Despite uncertainty in the estimation of amounts of $\mathrm{C}^{14}$ in the free body glucose of various patients as discussed above (cf., Results), it would nevertheless seem that in the labile, strongly ketotic diabetics two to three times as much ( $c a .4$ per cent versus 1.5 per cent) of the administered $\mathrm{C}^{14}$ appeared in glucose as in the nondiabetic subjects (2), while little if any more than the amount in controls appeared in the glucose of stable diabetic subjects with glucocorticoid excess. The results with labile diabetics, at least, are quite in agreement with the findings from normal and alloxan-diabetic rats given $2-C^{14}$-acetate and $6-C^{14}$ tripalmitin (46).

Due to the involvement of many unknown factors, such as the relative amounts of glycogen formed in the various patients, it would be inadvisable to draw conclusions from the $\mathrm{C}^{14}$ data regarding rates of total carbohydrate synthesis. Certainly the differences in general $\mathrm{C}^{14}$ content of glucose do not provide information as to the utilization of expected or unusual pathways. If, indeed, an excess of glucose was formed in the labile diabetics, the findings do not seem to bear out the usual concept that overproduction of glucose is more characteristic of diabetes of adrenal origin than of diabetes of the pancreatic, insulindeficient type. The possibility should not be overlooked that in the acidotic diabetics natural adrenal factors were operating more effectively than the administered synthetic steroid (47). Evidence on this point includes observations from isotopic data that a sevenfold greater than normal production of glucose resulted from administration of cortisone to rats, whereas only a twofold increase occurred in alloxan-diabetic rats (48). Findings from the present study may be viewed as more compatible with glucose turnover as observed in normal and diabetic humans (17) in whom overproduction of glucose was suggestively correlated with degree of ketosis in unstable diabetics. In view of the still possible utilization of unusual pathways discussed above and perhaps others not presently recognized, the question as to whether fatty acids may contribute in some unique way to excessive gluconeogenesis in certain diabetic situations may not yet be considered fully resolved.

\section{SUM MARY}

Production of glucose in various states of clinical diabetes has been investigated with five patients. Two of these were young, labile diabetics who were in a condition of marked ketosis and acidosis, one was a stable diabetic with some clinical evidence of increased adrenal activity, and two were middle-aged, obese, stable diabetics to whom a large dose of prednisone (delta-1-cortisone) had been administered shortly before study. Mild ketosis was present in the latter two subjects.

Each patient was injected intravenously with a trace amount of 1-C $\mathrm{C}^{14}$-acetate followed in two hours by collection of blood and in some cases various urinary samples for glucose analysis. Degradation of glucose (by fermentation with Leuconostoc mesenteroides) and analysis of $\mathrm{C}^{14}$ content of each carbon position showed virtually all of the glucose $C^{14}$ (96 to 98 per cent) to be in the 3 and 4 carbons, as has been previously observed with animals and nondiabetic humans. These findings are consistent with the operation 
of the tricarboxylic acid cycle and/or fixation of carbon dioxide followed by reversal of glycolytic reactions as the means of appearance of $\mathrm{C}^{14}$ in glucose. The occurrence of the conventional glucose labeling pattern fails to provide evidence for utilization of special metabolic pathways by which gluconeogenesis (net gain in carbohydrate) from fat could occur in possibly predisposing nutritional and hormonal conditions. If certain pathways, principally involving ketone bodies as intermediates, had been operational, then the 1, 2, 5, and 6 carbons of glucose would have been substantially labeled. The findings do not exclude all possible reactions which could result in gluconeogenesis from fat.

Small amounts of tracer (less than 2 per cent of the total glucose $\mathrm{C}^{14}$ ) were present in each of the $1,2,5$, and 6 carbons in such a proportion as mainly to suggest derivation by reactions of the pentose phosphate cycle. $\mathrm{C}^{14}$ was present in these carbon positions in approximately the same pattern and amount as with nondiabetic humans.

In the labile diabetics with marked ketosis approximately 4 per cent of the administered $\mathrm{C}^{14}$ was estimated to be present in free body glucose two hours after injection, while in the stable diabetics with or without glucocorticoid administration about 2 per cent was found in glucose at this time. Since nondiabetic humans in corresponding studies showed an average of 1.5 per cent of administered $\mathrm{C}^{14}$ in glucose, the data are suggestive, though by no means conclusive, of an increased rate of carbohydrate synthesis from acetate in the labile, acidotic diabetics. The data would not distinguish between the utilization of special or common pathways of glucose synthesis.

\section{ACKNOWLEDGMENTS}

The authors wish to thank Mrs. Elizabeth M. Jellett and Mr. Paul M. Tocci for able technical assistance, Dr. Donald D. Van Slyke for helpful advice in the preparation of the manuscript, and Drs. Howard A. Eder and Anne Carter for cooperation in the study of Subject M. M. at Kings County Hospital, Brooklyn, N. Y.

\section{REFERENCES}

1. Shreeve, W. W. Glucogenesis from 1-C $C^{14}$-acetate in non-diabetic and diabetic man. Fed. Proc. 1956, $15,354$.

2. Shreeve, W. W. Pathways of carbohydrate formation in man. I. Isotope distribution in glucose from nondiabetic subjects given 1- $\mathrm{C}^{\mathbf{1}}$-acetate. $\mathrm{J}$. clin. Invest. 1958, 37, 999.

3. Lifson, N., Lorber, V., Sakami, W., and Wood, H. G. The incorporation of acetate and butyrate carbon into rat liver glycogen by pathways other than carbon dioxide fixation. J. biol. Chem. 1948, 176, 1263.

4. Weinman, E. O., Strisower, E. H., and Chaikoff, I. L. Conversion of fatty acids to carbohydrate: Application of isotopes to this problem and role of the Krebs cycle as a synthetic pathway. Physiol. Rev. 1957, 37, 252.

5. Abraham, S., Chaikoff, I. L., and Hassid, W. Z. Conversion of $\mathrm{C}^{\mathbf{1 4}}$-palmitic acid to glucose. II. Specific glucose carbons labeled. J. biol. Chem. 1952, 195, 567.

6. Miller, B. F., and Van Slyke, D. D. A direct microtitration method for blood sugar. J. biol. Chem. 1936, 114, 583.

7. Mendel, B., Kemp, A., and Myers, D. K. A colorimetric micro-method for the determination of glucose. Biochem. J. 1954, 56, 639.

8. Michaels, G. D., Margen, S., Liebert, G., and Kinsell, L. W. Studies in fat metabolism. I. The colorimetric determination of ketone bodies in biological fluids. J. clin. Invest. 1951, 30, 1483.

9. Peters, J. P., and Van Slyke, D. D. Quantitative Clinical Chemistry, Vol. II, Methods. Baltimore, Williams and Wilkins Co., 1932, p. 283.

10. Peters, J. P., and Van Slyke, D. D. Quantitative Clinical Chemistry, Vol. II, Methods. Baltimore, Williams and Wilkins Co., 1932, pp. 353 and 691.

11. Kingsley, G. R. A rapid method for the separation of serum albumin and globulin. J. biol. Chem. 1940, 133, 731.

12. Hough, L., Jones, J. K. N., and Wadman, W. H. Quantitative analysis of mixtures of sugars by the method of partition chromatography. Part IV. The separation of the sugars and their methylated derivatives on columns of powdered cellulose. J. chem. Soc. 1949, 4, 2511.

13. Kinsell, L. W., Michaels, G. D., Margen, S., Partridge, J. W., Boling, L., and Balch, H. E. The case for cortical steroid hormone acceleration of neoglucogenesis from fat in diabetic subjects. A summary of five years' investigative work. J. clin. Endocr. 1954, 14, 161.

14. Soskin, S., and Levine, R. Carbohydrate Metabolism. Chicago, University of Chicago Press, 1952, p. 150.

15. Drury, D. R. The significance of the $D: N$ ratio and its bearing on the mechanism of diabetes mellitus. J. clin. Invest. 1942, 21, 153.

16. Peters, J. P., and Van Slyke, D. D. Quantitative Clinical Chemistry, Vol. I, Interpretations. Baltimore, Williams and Wilkins Co., 1946, p. 141.

17. Shreeve, W. W., Baker, N., Miller, M., Shipley, R. A., Incefy, G. E., and Craig, J. W. $C^{14}$ studies in carbohydrate metabolism. II. The oxidation of glu- 
cose in diabetic human subjects. Metabolism 1956, $5,22$.

18. Bernstein, I. A., Lentz, K., Malm, M., Schambye, P., and Wood, H. G. Degradation of glucose-C $\mathrm{C}^{14}$ with Leuconostoc mesenteroides; alternate pathways and tracer patterns. J. biol. Chem. 1955, 215, 137.

19. Deuel, H. J., Jr., and Morehouse, M. G. The interrelation of carbohydrate and fat metabolism. Advanc. Carbohyd. Chem. 1946, 2, 119.

20. Dann, M. The question of carbohydrate production from fat with special reference to diabetes. Yale J. Biol. Med. 1933, 5, 359.

21. Rapport, D. The interconversion of the major foodstuffs. Physiol. Rev. 1930, 10, 349.

22. Korkes, S. A potential pathway from $C_{2}$ to $C_{3}$ and the question of gluconeogenesis from fatty acids. Brookhaven Symposia in Biology, No. 5, Major Metabolic Fuels, 1952, p. 192.

23. Haarmann, W., and Schroeder, E. Uber die Umwandlung von Fett in Zucker. II. Biochem. Z. 1938, 296, 35.

24. Blixenkrone-M $\phi 1$ ler, N. Kohlehydrat- und Ketonkörperbildung aus Fettsaüren in der künstlich durchströmten Katzenleber. Hoppe-Seylers $Z$. physiol. Chem. 1938, 252, 137.

25. Barfod, B. Gluconeogenesis from oleic acid in the perfused cat's liver. Acta Physiol. scand. 1953, 28, 41.

26. Kronfeld, D. S. Effect of butyrate administration on blood glucose in sheep. Nature (Lond.) 1956, 178, 1290.

27. Kleiber, M., Black,.A. L., Brown, M. A., Luick, J., Baxter, C. F., and Tolbert, B. M. Butyrate as a precursor of milk constituents in the intact dairy cow. J. biol. Chem. 1954, 210, 239.

28. Sakami, W., and Lafaye, J. M. The metabolism of acetone in the intact rat. J. biol. Chem. 1951, 193, 199.

29. Hobbs, D. C., Hill, R. J., and Koeppe, R. E. Metabolism of acetone-2- $\mathrm{C}^{16}$ in the intact rat. Fed. Proc. 1957, 16, 197.

30. Rudney, H. Propanediol phosphate as a possible intermediate in the metabolism of acetone. J. biol. Chem. 1954, 210, 361.

31. Grégoire, P.-E. Action des globules rouges sur l'acide diacétique. Bull. Soc. Chim. biol. (Paris) 1933, 15, 1094.

32. Shaw, W. N., Dituri, F., and Gurin, S. Lipogenesis in particle-free extracts of diabetic liver. II. Experimental diabetes. J. biol. Chem. 1957, 226, 417.

33. Lorber, V., and Cook, M. The metabolism of n-butyrate- $\mathrm{C}^{\mathbf{1 4}}$ by mammalian heart muscle. J. biol. Chem. 1955, 215, 823.
34. Meyer, J., and Bow, T. M. Metabolism of acetoacetate-3-C $\mathrm{C}^{\mathbf{1}}$ by mammalian heart muscle. Proc. Soc. exp. Biol. (N. Y.) 1956, 91, 608.

35. Thunberg, T. Zur Kenntnis des intermediären Stoffwechsels und der dabei wirksamen Enzyme. Skand. Arch. Physiol. 1920, 40, 1.

36. Seaman, G. R., and Naschke, M. D. Reversible cleavage of succinate by extracts of Tetrahymena. J. biol. Chem. 1955, 217, 1.

37. Topper, Y. J., and Stetten, DeW., Jr. Formation of "acetyl" from succinate by rabbit liver slices. J. biol. Chem. 1954, 209, 63.

38. Barron, E. S. G., and Ghiretti, F. The pathways of acetate oxidation. Biochim. biophys. Acta 1953, 12, 239.

39. Weil-Malherbe, H. Studies on brain metabolism. II. Formation of succinic acid. Biochem. J. 1937, 31, 299.

40. Wong, D. T. O., and Ajl, S. J. Significance of the malate synthetase reaction in bacteria. Science 1957, 126, 1013.

41. Kornberg, H. L., and Krebs, H. A. Synthesis of cell constituents from $\mathrm{C}_{2}$-units by a modified tricarboxylic acid cycle. Nature (Lond.) 1957, 179, 988.

42. Madsen, N. B. Test for isocitrase and malate synthetase in animal tissues. Biochim. biophys. Acta 1958, 27, 199.

43. Glock, G. E., and McLean, P. A preliminary investigation of the hormonal control of the hexose monophosphate oxidative pathway. Biochem. J. 1955, $61,390$.

44. Milstein, S. W. Oxidation of specifically labeled glucose by rat adipose tissue. Proc. Soc. exp. Biol. (N. Y.) 1956, 92, 632.

45. Marks, P. A., and Feigelson, P. Pathways of glycogen formation in liver and skeletal muscle in fed and fasted rats. J. clin. Invest. 1957, 36, 1279.

46. Strisower, E. H., Chaikoff, I. L., and Weinman, E. O. Conversion of $\mathrm{C}^{\mathbf{1 4}}$-palmitic acid to glucose. I. Normal and diabetic rats. J. biol. Chem. 1951, 192, 453.

47. McArthur, J. W., Gautier, E., Swallow, K. A., Godley, A., MacLachlan, E. A., Terry, M. L., Hume, D., Crepeaux, J., Simeone, F. A., Keitel, H., and Berman, H. Studies concerning the role of the adrenal cortex in the pathologic physiology of diabetic acidosis. II. The identification of adrenalconditioned factors in the physiologic reaction to the stress of insulin deprivation. J. clin. Invest. 1954, 33, 437.

48. Welt, I. D., Stetten, DeW., Jr., Ingle, D. J., and Morley, E. H. Effect of cortisone upon rates of glucose production and oxidation in the rat. J. biol. Chem. 1952, 197, 57. 